\title{
Valuing student ideas morally, instrumentally, and intellectually
}

\author{
Amy D. Robertson \\ Seattle Pacific University, Department of Physics, \\ 3307 Third Avenue W, Suite 307, Seattle, WA, 98199-1997
}

\begin{abstract}
The importance of valuing student ideas in science education stands on firm empirical, theoretical, and moral grounds. However, the reasons for which one might value student ideas are often not explicitly distinguished, even if implicit distinctions are made in the literature. In this paper, I define and distinguish between three ways of valuing student ideas - moral, instrumental, and intellectual - and I suggest implications of these distinctions for teacher education and research.
\end{abstract}

PACS: $01.40 . \mathrm{Fk}, 01.40 . \mathrm{Ha}, 01.40 . \mathrm{jc}$

\section{INTRODUCTION}

The importance of valuing student ideas may arguably be called the "zeroth law of education research." Myriad studies have established the empirical and theoretical productivity of attending to and building on student thinking in the classroom. These practices are central to formative assessment [1] and to cognitive [2,3] and social $[4,5]$ theories of learning.

Often, we treat "valuing" as binary or as a spectrum: one either values student ideas, or one does not, or else one values student ideas more or less. In this paper, I distinguish between three ways of valuing student ideas: moral, instrumental, and intellectual. Valuing students' ideas morally may stem from an ethic of care: one cares for students as whole people and thus values their ideas. One may also value student ideas instrumentally, for their usefulness in accomplishing some instructional purpose, such as diagnosing a student's misunderstanding. Or one may value student ideas intellectually, for their disciplinary potential or for their sensibility in light of a student's experiences. All three represent valuing student ideas but have distinct implications for how these ideas are taken up instructionally.

In the following sections, I clarify these three definitions with illustrations from novice teacher reflections on practice. I show that these definitions are implicit in discussions of attending to student ideas in the literature, and I consider the implications of these theoretical distinctions for teacher education and future research. In a separate paper [6], Lovegren and I propose mechanisms that may promote shifts among different ways of valuing students' ideas.

\section{METHODOLOGY}

Novice teachers in the Seattle Pacific University (SPU) Learning Assistant (LA) Program (described in Lovegren and Robertson [6] and in Robertson, et al. [7]) are required to submit weekly teaching reflections in which they describe the impact of pedagogy or preparatory class discussions on their teaching practice. Over the course of two quarters during the 2012-2013 academic year, I (the pedagogy/prep course instructor) noticed different ways in which LAs valued student ideas and felt these differences could inform my own and others' sense of what it means to do so. To distinguish between different ways in which LAs were valuing student ideas, I used their teaching reflections to construct brief narratives that tracked the ways in which each LA valued student ideas at different points in time across the academic year. Based on patterns both within and across individual LAs, I collapsed the narratives into the three ways of valuing student ideas defined above. I then selected LA reflections that clearly and concisely illustrate the three ways of valuing. In this paper, I draw connections between these selected reflections (cases of the three ways of valuing I define) and the education research literature $[8,9]$.

This small sample size and case study analysis is appropriate for the purposes of challenging and extending theory about valuing student ideas [8-10]. My point is not to make a representative claim or to speak to the recurrence of specific categories within the data; it is to challenge the sufficiency of a binary- or spectrum-oriented way of thinking about valuing and to suggest implications for research and teacher education that follow from a more nuanced view of valuing student ideas.

\section{VALUING STUDENT IDEAS MORALLY}

Novice teachers may value student ideas as part of caring for students as whole people. This valuing of ideas is moral in the sense that it stems from an ethic of care $[11,12]$. Reasons to value student ideas morally include, for example, fostering student confidence or establishing a relationship in which students feel comfortable sharing their ideas. However, there is no explicit indication that a teacher who morally values her students' ideas does anything with the ideas other than to affirm the student in being heard. 
LAs value student ideas morally when they notice that students are sharing their ideas (but do not explicitly attend to the substance of those ideas) and when they describe their reasons for listening to students in language consistent with an ethic of care (e.g., when they want their listening to communicate care or build students' confidence). For example, one LA, Brittany", writes: "It's so refreshing [when]...[t] hey just want to share their ideas because they (hopefully) know that I care what they think!" Another LA, Taylor, writes: "When a teacher shuts down a student's line of thinking, it can be damaging....For young students or students that lack confidence, this can be a problem."

\section{VALUING STUDENT IDEAS INSTRUMENTALLY}

Novice teachers may also value student ideas for their usefulness in accomplishing particular teaching and learning goals, often student achievement of the correct answer. Students' ideas thus become instruments in the teacher's trade. Examples include use of student ideas as instruments for diagnosing misunderstandings and/or as instructional exemplars.

\section{A. Student ideas are instrumental in diagnosing misunderstandings.}

Theories of conceptual change assert that students construct new understandings on the basis of their existing ideas [13]. Some researchers and practitioners interpret this to mean that effective teaching begins by understanding student ideas and then uses this understanding as a starting place in bringing students toward the canon [14,15].

SPU LAs value student ideas as diagnostic tools, either for determining that students have not understood the material (a 'get-it-or-don't' conception of formative assessment [16]) or for determining what, specifically, the students do not understand. One LA, David, embodies the former when he describes how his diagnosis informs his decision to lead students to the correct answer: "I began by asking probing questions about their [free body diagrams]. After a few of those, I realized that they really didn't understand the material. After that, I started to use leading questions to help guide them towards the correct response." Another LA, Ryan, diagnoses a specific student misunderstanding: "After probing for a minute [I] figured out that the student had forgotten what the cos[ine] (theta) meant in work. [Ryan then describes a series of leading questions about the cosine of various angles and the thetadependence of the expression for work.] Leading through these questions she was able to see how that one variable was the determining factor in whether or not work was positive or negative."

\footnotetext{
${ }^{1}$ All names in this paper are pseudonyms
}

\section{B. Student ideas can serve as instructional exemplars.}

LAs also treat correct student ideas as instrumental to enhancing other students' understandings. They describe instances in which they put examples of correct student reasoning on display, valuing the potential of this reasoning for bringing other students toward the canon. For example, David writes: "I...immediately noticed that one student began to provide correct responses [to my questions], while the others were lagging...behind...I asked her to explain how she came to that answer. As she walked through it, and I continued to ask questions, the other students start[ed] realizing how she got there...[O]nce I found someone who understood what was going on, I used their understanding to... spread it to the rest of the table."

\section{VALUING STUDENT IDEAS INTELLECTUALLY}

Ideas may also be valued intellectually - as meaningful and complex products of students' efforts to make sense of their experiences. LAs intellectually value student ideas when they treat these ideas as sensible, productive starting places for learning [17].

Intellectual valuing is both distinct from and related to moral and instrumental valuing. Both morally and intellectually valuing student ideas involve appreciating student ideas for what they are, rather than what the teacher wishes them to be $[11,12]$. However, intellectual valuing of student ideas includes attention to the disciplinary substance of student ideas [18] - the "beginnings of science" inherent in their thinking - whereas moral valuing attends to students as whole people but does not specifically attend to the substance of student thinking.

In addition, although instrumental and intellectual value for student ideas both involve building on those ideas, they are distinct with respect to whose meaning is at the center of the instructor's attention. For example, instances of intellectually valuing student ideas build more directly on and are consistent with the meaning that students are making of their disciplinary experiences. Instantiations of instrumentally valuing student ideas, on the other hand, often follow a logical path from the instructor's diagnosis of student thinking to the canonical answer, in many cases via a path that does not depend on the student's original meaning.

\section{A. Student ideas are sensible.}

LAs value student ideas intellectually by making sense of canonically incorrect student reasoning, seeking to understand why a student may be responding the way that they are. For example, one LA, Jess, discusses a student's conflation of tension and linear mass density. She determines that the student's answer makes sense in light of the appearance of the spring: "She...said that the spring just seemed tenser...I knew that she ha[d] interchanged the 
word tense to mean the tension in the spring. She thought that since spring 1 was tenser, it had more tension. This is true in the sense of how people feel tension or what we believe tension to be, but this didn't necessarily fall in line with the physics definition of tension..."

\section{B. Student ideas are productive starting places for instruction.}

LAs also illustrate intellectual value for student ideas when they treat student ideas as productive starting places for instruction. In particular, LAs describe their use of explanations that build on student ideas and experiments that test student ideas. For example, Emily writes: "One of the...misconceptions in [the "Conservation of Angular Momentum"] tutorial is that students do not realize that linear momentum and angular momentum are each conserved...[A few students] told me that momentum is conserved, and that therefore, some of the linear momentum turns into angular momentum, and the spinning system travels slower. The kernel [of] truth in this situation is that momentum is conserved. And since that's what the students have been taught, they applied it to the new situation. I responded by helping them revise their original statements from "momentum is conserved" to "linear momentum is conserved, and angular momentum is conserved." It was much easier to take the step from the foundation that they already had than it would have been to restart from scratch." In this quote, Emily sees the "beginnings" of conservation reasoning in her students' thinking. She treats her students' use of incorrect conservation principles as a "kernel of truth" [6] that she can refine (i.e., as opposed to a misunderstanding to replace or confront).

Another LA, Sarah, designs an experiment to test a student's idea about the reflection of pulses from a fixed end: "This week... a student was struggling with how a fixed end of a wave works...[S]he explained that her idea was that the wave would go through [the] fixed point completely leading to a flat line and then it would return. We tested it, but it never flat lined which disproved her hypothesis. She was frustrated that she had no further ideas so I pulled out a kernel of truth, that the wave would go through and return, and suggested that the portion of the wave that goes through returns leading to superposition." The experiment that Sarah proposes tests the idea that the student offers. When the student realizes that her idea is incorrect, Sarah proposes an alternative explanation that connects to the student's original idea; she highlights that the wave does go through and return, but it begins to return as soon as the wave makes contact with the fixed end of the spring.

\section{MORAL, INSTRUMENTAL, AND INTELLECTUAL VALUING IN THE LITERATURE}

My definitions of moral, instrumental, and intellectual valuing highlight and name implicit distinctions made in literature on attending and responding to student thinking. For example, Jacobs, Lamb, Philipp, and Shappelle [19] asked teachers how they would respond to a video-recorded episode of a student - Rex - solving a mathematics problem. They distinguish between teachers' answers on the basis of the extent to which they attend to Rex's mathematical thinking, writing: "Other responses focused on... nurturing Rex's affect without any reference to his past or future mathematical understandings ("'It is hard but let's try - teachers love it when you try!' I would always try to keep the child's self-esteem high. I wouldn't want him to feel like he wasn't smart.")" Here, Jacobs, et al., describe a way of valuing Rex's ideas that attends to his confidence and well-being but not to the mathematical substance of his ideas; in my words, this response instantiates moral valuing. In a separate chapter of the same book, Erickson [20] describes different ways in which teachers saw and made sense of student thinking, writing: “...noticing was usually highly instrumental - tactically opportunistic and triage-like - what was attended to was that which required action by the teacher." On the other hand, "noticing was occasionally non-instrumental - appreciative rather than tactical - but that was atypical." Here, Erickson distinguishes between what I would call instrumental and intellectual valuing of students' ideas.

I use these examples not only to make the point that the three ways of valuing student ideas that I define in this paper extend beyond my small sample of LAs - i.e., that they are more general - but also to show that my work highlights and gives name to distinctions and categories that others feature in their discussions of attending to student thinking. These definitions and distinctions have important implications for teacher education and suggest avenues for future research, discussed in the next section.

\section{CONCLUSION}

This paper defines and distinguishes between three different ways of valuing student ideas: moral, instrumental, and intellectual. These definitions challenge a binary or spectrum-like view of "valuing": the novice teachers featured in this paper embody different ways of valuing student ideas, as opposed to embodying different levels or degrees of valuing student ideas. To be clear, I do not mean to suggest that these are the only three ways of valuing student ideas; my goal has not been to map out the space. Instead, my descriptions and illustrations are meant to turn our attention toward characterizing how and for what purpose teachers value student ideas, rather than strictly focusing on whether or not or how much they do so. 
Although drawn from a specific group of teachers in a specific context, the connection between this case and the literature highlights the theoretical significance of these definitions and the potential for this work to broaden readers' awareness in similar situations [21,22].

In particular, this work has implications for teacher education. Teacher educators who care about valuing student ideas may (unconsciously) take a stance on what it means to do so; this stance may limit teacher educators' vision for the ways in which their teacher candidates are already valuing student thinking. Further, certain ways of valuing student ideas may be "ways in" to other ways of doing so, such that teacher educators who wish to promote one way of valuing student ideas can attend to and build on the ways in which their teacher candidates are already instantiating these practices. For example, caring for students morally could be a "way in" to intellectually valuing their ideas; teachers may come to see caring for their students as scientific thinkers as an extension of caring for them as whole people. This possibility of moving between ways of valuing is substantiated by my data: I found that novice teachers moved among ways of valuing, and they often valued student ideas in multiple ways at a single point in time; they did not progress through them, nor did they stably embody a single form of valuing. My three definitions may support teacher educators in identifying ways in which their teacher candidates value student ideas, or in assessing the extent to which teachers are moving toward targeted ways of valuing.

1. P. Black and D. Wiliam, Assessment Educ. 5 (1), 7-74 (1998).

2. R. Driver and B. Bell, School Sci. Rev. 67, 443-456 (1986).

3. J. Bransford, A. Brown, and R. Cocking, How People Learn: Brain, Mind, Experience, and School, Washington, D.C.: National Academy Press, 2000.

4. L. S. Vygotsky, Mind in Society: The Development of Higher Psychological Processes, USA: Harvard University Press, 1978.

5. R. T. Putnam and H. Borko, Educ. Res. 29 (1), 4-15 (2000).

6. C. E. Lovegren and A. D. Robertson, "Development of Novice Teachers' Views as Sensible and Productive," in Proceedings of the 2013 Physics Education Research Conference, edited by P. V. Engelhardt, A. D. Churukian, and D. L. Jones (Portland, OR), pp. 225-228.

7. A. D. Robertson, E. P. Eppard, L. M. Goodhew, E. L. Maaske, H. C. Sabo, F. C. Stewart, D. L. Tuell, and S. T. Wenzinger, APS Forum on Education Newsletter, 7-14 (Summer 2014).

8. R. K. Yin, Case study research: Design and methods, Thousand Oaks: SAGE Publications, Inc., 2003.

9. F. Erickson, "Qualitative Methods in Research on Teaching", in Handbook of Research on Teaching, edited by M. C. Wittrock, New York: Macmillan, 1986, pp. 119-161.

10. M. Eisenhart, "Generalization for Qualitative Inquiry," in Generalizing from Educational Research: Beyond Qualitative and Quantitative Polarization, edited by K. Ercikan and W. M. Roth, New York: Routledge, 2009, pp. 51-66.

11. N. Noddings, Am. J. Educ. 96 (2), 215-230 (1988).

12. M. Mayeroff, On Caring, New York: Harper Perennial, 1971.
These theoretical distinctions also suggest open questions for future research. Many teachers care about valuing student ideas because they want students to be agentive learners, or because they want students to see their voices as central to the flow of instruction $[23,24]$. That there are different ways in which novice teachers value student ideas suggests that there may also be different ways in which students experience their ideas as valuable. For example, students may feel that their teachers care for them as whole people, including what they say in class (moral), or they may feel that their ideas serve as an important diagnostic for what they understand (instrumental). Researchers who wish to understand how students experience the flow of instruction - including the ways in which students feel their ideas matter - may want to attend to these distinctions as well.

\section{ACKNOWLEDGMENTS}

This material is based upon work supported by the National Science Foundation under Grant Nos. 0822342, 122732, and 1418211. I am grateful for the substantive contributions of Learning Assistants B. Clarke, A. Wing, A. Frazier, C. Lovegren, E. Maaske, L. Muñoz, J. Paige, K. Rininger, H. Sabo, C. Schmarr, F. Stewart, and S. Wenzinger. I also wish to acknowledge the partnership of B. Lippitt. Finally, I wish to thank C. Alvarado, A. Daane, L. DeWater, K. Gray, S. McKagan, J. Richards, R. Scherr, L. Seeley, and S. Vokos for their thoughtful feedback.

13. G. J. Posner, K. A. Strike, P. W. Hewson, and W. A. Gertzog, Sci. Educ. 66 (2), 211-227 (1982).

14. L. C. McDermott, Am. J. Phys. 59 (4), 301-315 (1991).

15. J. A. Morrison and N. G. Lederman, Sci. Educ. 87 (6), 849867 (2003).

16. V. K. Otero, J. Teach. Educ. 57 (3), 247-255 (2006).

17. J. P. Smith III, A. A. diSessa, and J. Roschelle, J. Learn. Sci. 3 (2), 115-163 (1993).

18. J. E. Coffey, D. Hammer, D. M. Levin, and T. Grant, J. Res. Sci. Teach. 48 (10), 1109-1136 (2011).

19. V. R. Jacobs, L. L. C. Lamb, R. A. Philipp, and B. P. Schappelle, "Deciding How to Respond on the Basis of Children's Understandings," in Mathematics Teacher Noticing: Seeing Through Teachers' Eyes, edited by M. G. Sherin, V. R. Jacobs, and R. A. Philipp, New York: Routledge, 2011, pp. 97-116.

20. F. Erickson, "On Noticing Teacher Noticing," in Mathematics Teacher Noticing: Seeing Through Teachers' Eyes, edited by M. G. Sherin, V. R. Jacobs, and R. A. Philipp, New York: Routledge, 2011, pp. 17-34.

21. J. A. Maxwell, Harvard Educ. Rev. 62 (3), 279-300 (1992).

22. G. Wehlage, "The purpose of generalization in field study research", in The study of schooling, edited by T. Papkewitz and B. Tabchmie, New York: Praeger, 1981, pp. 211-226.

23. K. Gallas, Talking Their Way Into Science: Hearing Children's Questions and Theories, Responding With Curricula, New York: Teachers College Press, 1995.

24. D. Hammer, F. Goldberg, and S. Fargason, Rev. Sci. Math. ICT Educ. 6 (1), 51-72 (2012). 